\title{
Special nutrition intervention is required for muscle protective efficacy of physical exercise in elderly people at highest risk of sarcopenia
}

\author{
A Molnár ${ }^{1}$, I Jónásné Sztruhár ${ }^{2}$, ÁA Csontos ${ }^{3}$, Cs Ferencz ${ }^{4}$, Sz Várbíró $^{5}$, B Székács ${ }^{6}$ \\ ${ }^{1}$ School of Ph.D. Studies, Doctoral School of Pathological Sciences, Health Science Research, Semmelweis \\ University, Budapest, Hungary \\ ${ }^{2}$ Old Age Home of the Municipality of Budapest, Hungary \\ ${ }^{3}$ 2nd Department of Medicine, Semmelweis University, Budapest, Hungary \\ ${ }^{4}$ Geronto-Psychiatric Rehabilitation Department, Szent Imre University Teaching Hospital, Budapest, Hungary \\ ${ }^{5}$ 2nd Department of Gynecology and Obstetrics, Semmelweis University, Budapest, Hungary \\ ${ }^{6}$ 2nd Department of Medicine, Section of Geriatrics, Semmelweis University, Budapest, Hungary
}

Received: December 9, 2015

Accepted: August 8, 2016

Progressive loss of muscle mass and strength is a physiological consequence of aging, and without interventions, it usually deteriorates into sarcopenia. In this study, the hypothesis that combined special nutritional-physiotherapeutical intervention to prevent or reverse this biological deterioration in elderly people was tested. The effects of the regular resistance muscle training $(\mathrm{PT}, n=17)$ alone and the combined exercise + special nutrition therapy containing whey protein and vitamin $\mathrm{D}(\mathrm{PT}+\mathrm{NT}, n=17)$ were monitored for 3 months in 34 elderly patients (12 men and 22 women; mean age: 66.47 years) randomly distributed into two groups at a long-term care facility. Physical exercise alone did not result in significant improvement in skeletal muscle mass or strength, whereas combined intervention significantly increased the muscle strength $(22.51 \pm 2.35$ vs. $24.54 \pm 2.65, \bar{x} \pm \mathrm{SEM}, \mathrm{kg}$, $p=0.027)$. When therapeutic responses to the intervention were compared, a significant advantage of PT $+\mathrm{NT}$ over PT was found. The same trend was found when the non-significant post-therapeutic alterations $\left(\chi^{2}\right.$ test) of the distribution of normal vs. pre-sarcopenic + sarcopenic conditions within the two groups were compared. Combined intervention $(\mathrm{PT}+\mathrm{NT})$ is necessary for the efficient protection of the musculature in the high-risk elderly patients.

Keywords: muscle mass, muscle strength, sarcopenia, physiotherapy, nutrition intervention, nutrition therapy

\section{Introduction}

Progressive loss of muscle mass and strength is a physiological process during advanced aging (14). Sarcopenia, which is the critical combined loss of the skeletal muscle mass, strength, and functional capacity, is a pathologic phase of this biological deterioration (14). Frailty, immobility, loss of self-maintenance, malnutrition, cachexia, and death are all consequences of severe progressive sarcopenia. A gradual decrease in muscle mass (19, 20, 23) may be observed already from the age of 40-50 years, and the prevalence of sarcopenia significantly increases with advanced age $(5,21,30)$. In institutionalized elderly people, increasing deterioration of musculature leading to progressive sarcopenia is leading risk $(3,21,22)$. The prevalence of the different stages of the loss of muscle mass and strength

Corresponding author: Dr. Szabolcs Várbíró MD, $\mathrm{PhD}$

2nd Department of Gynecology and Obstetrics, Semmelweis University

78/a Üllői road, H-1082 Budapest, Hungary

Phone: +36 20335 9099; Fax: +36 1333 4934; E-mail: varbiroszabolcs@gmail.com 
ranges from $10 \%$ to $60 \%$ in the elderly people $(5,21,30)$. The geriatric syndrome sarcopenia - which is a critical stage of this neuromuscular problem - is of complex etiology and its clinical appearance has complex consequences and pathological components superposed to the physiological muscle aging. Increased physical activity may slow but not halt this chronic process in the aged high-risk elderly group $(25,32)$. Proposed pillars of relatively successful therapeutic strategies are regular muscle training and specific nutritional therapy (increased intake of protein and complimentary nutrients) $(7,15,27-29)$. Whey protein, a fast-acting protein that is quickly digested and becomes fast-absorbing peptides and amino acids, can potentially be the most effective in maintaining adequate anabolic/catabolic balance in the musculature of elderly individuals. Daily protein $(1.2-1.5 \mathrm{~g} / \mathrm{kg} /$ bodyweight $)$ and bolus protein intakes (at least 25-30 g of high-quality protein per meal) could sufficiently stimulate muscle protein synthesis in both the healthy and sarcopenic elderly people $(2,9,13$, 24). It is now clear that the anabolic efficacy of the various amino acids is different, and a complex mixture of essential amino acids with an added extra quantity of leucine (8) is the most efficient. Increased vitamin D intake is also an essential therapeutic component in the prevention of not only osteoporosis but also sarcopenia $(7,15,28,29)$. In spite of these promising findings, it is known that the sensitivity of the muscle protein synthesis in the elderly people is very low to anabolic stimuli (10). Our hypothesis was that in the case of high-risk elderly patients in institutions, only the combination of physical exercise and scientifically planned optimal nutritional intervention (FortiFit, Nutricia providing all the above-mentioned components) may halt or slow the progress of the critical deterioration of the musculature. This hypothesis was tested at a large long-term care facility.

\section{Materials and Methods}

The study was approved by the local institutional Committee of Science and Research Ethics and was performed in accordance with the Helsinki declaration. All patients agreed to participate and provided informed consent.

Elderly people with comorbidities or comorbid conditions in nursing or care homes are at very high risk of critical muscle mass and strength loss, sarcopenia, falls, suboptimal response to therapy, and frailty syndrome. The primary objective of this study was to compare the effect of combined nutrition and exercise therapy to exercise therapy alone on the reduction of progressive loss of muscle mass and strength in the elderly people with comorbid conditions (15). The secondary objective was to compare the prevalence of normal or sarcopenic muscle status in elderly patients receiving exercise or exercise + nutritional intervention.

A total of 34 elderly patients, as voluntary subjects, were randomly selected and distributed into two groups (patients were randomized on initial muscle mass and strength because the study focused to avoid initial inter-group differences of muscle mass and strength) with $17+17$ members for a 3-month therapeutic intervention program at a large long-term care facility in Budapest. The basic primary selection criteria were as follows: the subjects complained of muscle strength loss but had the ability to adhere to the study protocol, i.e., suitable mobility and mental state. About 30 participants had normal cognitive function, and two participants in the PT group and also two participants in the PT + NT group had mild cognitive disturbance ( $>15$, defined by a Mini-Mental State Examination). Patients were excluded from the study if it was anticipated that the physical and the medical nutrition 
therapies could not be carried out due to previous underlying causes, such as malignant disease 5 years preceding the study, kidney failure, significant liver disease, poor cardiac status (pacemakers), or such physical-mental handicaps that made it impossible for the patient to fully participate in the physiotherapy regime.

Diagnostic procedures were as follows: first, evaluation of patients based on the inclusion and exclusion criteria then, the measurement of the skeletal muscle mass $(\mathrm{kg})$ and the fat-free mass $(\mathrm{kg})$ carried out by bioelectrical impedance analysis (InBody 370 device); the derivation of fat-free mass index (FFMI, $\mathrm{kg} / \mathrm{m}^{2}$ ) and muscle strength (handgrip) was done by electronic hand dynamometer (Carmy EH101 device), and muscle function (the short physical performance, SPPB) was measured according to the latest methodological techniques discussed in the consensus papers $(6,14)$. Body composition was measured by InBody analyzer, with each patient having fasted, urinated, and undressed except for underwear. All jewelry and wristwatches were removed before the measurement. The diagnosis of pre-sarcopenia and sarcopenia was established on the basis of the summed muscle mass (fat-free mass), muscle strength (handgrip), and muscle performance (SPPB) results $(6,14)$. The cut-off points of sarcopenia are based on the FFMI (data from bioimpedance analysis: men FFMI $<17 \mathrm{~kg} / \mathrm{m}^{2}$; women FFMI $<15 \mathrm{~kg} / \mathrm{m}^{2}$ ), the handgrip measurement adjusted for body mass index (BMI, $\mathrm{kg} / \mathrm{m}^{2}$ ) and gender (men: $\mathrm{BMI} \leq 24 \leq$ $29 \mathrm{~kg}$, BMI $24.1-26 \leq 30 \mathrm{~kg}$, BMI $26.1-28 \leq 30 \mathrm{~kg}$, BMI $>28 \leq 32 \mathrm{~kg}$; women: $\mathrm{BMI} \leq$ $23 \leq 17 \mathrm{~kg}$, BMI 23.1-26 $\leq 17.3 \mathrm{~kg}$, BMI 26.1-29 $\leq 18 \mathrm{~kg}$, BMI $>29 \leq 21 \mathrm{~kg}$ ), and the SPPB $<8$ (SPPB: standing balance, gait speed, and chair sit-to-stand) $(6,12,14)$. All the above-mentioned parameters were measured both at the start and at the end of the study.

All the patients in both the groups with $17+17$ members participated in the same physiotherapeutic program. The program provided regular, standard length physiotherapy sessions. The physiotherapy session, which was led by a certified physiotherapist, mostly consisted of strengthening exercise and included complex exercises. This regime was standardized for both groups (30 min twice a week). The regime included a 5-min warm-up, resistance band muscle strengthening exercises for both the upper and the lower limbs, core strengthening exercises performed in a sitting position, followed by muscle strengthening and stretching exercises. The first group (5 men and 12 women) received only this standard physiotherapy (PT group) for 3 months. However, the second group ( 7 men and 10 women) was provided with an additional special muscle protecting nutritional therapy (NT) for the same period (PT + NT group). It is important to note that in this study, it was not possible to establish a "real" control group with no physiotherapy at all, as allowing progressive muscle mass loss and the consequent frailty of highly vulnerable elderly patients would have been unethical.

The medical nutrition intervention was based on a recently developed consensus regarding the potentially efficient muscle protecting nutritional components in the elderly people $(7,8,15,28,29)$. Patients were randomized to receive either the intervention of physiotherapy (PT) or the physiotherapy combined with the nutrition therapy (PT + NT) (NT with FortiFit, oral nutritional supplement, and food for special medical purposes). The product contained $20 \mathrm{~g}$ whey protein, $10 \mathrm{~g}$ essential amino acid mixture, $3 \mathrm{~g}$ total leucine, $9 \mathrm{~g}$ carbohydrates, $3 \mathrm{~g}$ fat, $800 \mathrm{IU}$ vitamin $\mathrm{D}$, and a mixture of vitamins, minerals, and fibers per serving. It was provided as a $40 \mathrm{~g}$ powder to be reconstituted with $125 \mathrm{ml}$ of water and was offered twice daily, before breakfast and before lunch, to provide an adequate bolus of protein in addition to the meals (2). 


\section{Statistical analysis}

Comparisons between the two groups were made by two-sample $t$-tests, and changes within a group (comparisons between parameters at the beginning and at the end of the study) were tracked with one-sample $t$-tests. In both cases, $p<0.05$ was considered significant. The results are shown as the mean $\pm \mathrm{SEM}$. The statistical comparisons on the distribution of normal or pre-sarcopenic/sarcopenic conditions in the two groups were carried out by $\chi^{2}$ test (distribution before vs. after the 3-month interventions in the PT and PT + NT groups/intragroup comparisons, then the intra-group changes were compared with each other, as intergroup comparisons). Excel and GraphPad Prism software were used for the statistical analysis.

\section{Results}

\section{Baseline physiological parameters}

The patients were randomized by initial muscle mass and strength; at the beginning of the study, no significant difference was found between the two groups regarding age [PT group $66.35 \pm 1.79$ vs. PT + NT group $66.59 \pm 1.63$ years, n.s.], muscle mass (PT group $24.03 \pm$ $1.38 \mathrm{~kg}$ vs. PT + NT group $21.86 \pm 1.22 \mathrm{~kg}$, n.s.), muscle strength (PT group $23.73 \pm 2.06 \mathrm{~kg}$ vs. PT + NT group $22.51 \pm 2.35 \mathrm{~kg}$, n.s.), muscle performance value (SPPB scores: PT group $9.11 \pm 2.87$ vs. PT + NT group $6.88 \pm 3.65$, n.s.), and height (PT group $159.5 \pm 2.9 \mathrm{~cm}$ vs. $\mathrm{PT}+\mathrm{NT}$ group $162.8 \pm 2.4 \mathrm{~cm}$, n.s.). The initial values of body weight in PT group were $71.47 \pm 3.26 \mathrm{~kg}$ vs. in PT $+\mathrm{NT}$ group were $59.87 \pm 3.35 \mathrm{~kg}(p<0.05)$. It should be noted that the randomization was focused on the muscle mass and strength. However, as the slight intergroup difference remained also after the interventions and the intra-group changes did not show any inter-group differences $(\Delta \mathrm{PT} 0.388 \pm 1.162 \mathrm{~kg}$ vs. $\Delta \mathrm{PT}+\mathrm{NT} 1 \pm 0.643 \mathrm{~kg}$, n.s. $)$, it did not influence the therapeutic responses of indexed values of muscle mass and strength parameters for evaluating the stages or absence of sarcopenia.

\section{Responses of skeletal mass and strength to interventions}

Muscle strength and muscle mass values following the 3-month PT and PT + NT interventions: contrary to the tendency of progression usually encountered in sarcopenia, no significant changes were found (Fig. 1) either in skeletal muscle mass or in muscle strength in the PT group in comparison to the baseline values measured at the beginning of the study (skeletal muscle mass before vs. after: $24.03 \pm 1.38 \mathrm{~kg}$ vs. $22.98 \pm 1.41 \mathrm{~kg}, \bar{x} \pm \mathrm{SEM}$, n.s.; muscle strength before vs. after: $23.73 \pm 2.056 \mathrm{~kg}$ vs. $22.18 \pm 2.19 \mathrm{~kg}, \bar{x} \pm \mathrm{SEM}, \mathrm{n} . \mathrm{s}$.). In the PT + NT group, the skeletal muscle mass (skeletal muscle mass before vs. after: $21.86 \pm$ $1.21 \mathrm{~kg}$ vs. $22.26 \pm 1.22 \mathrm{~kg}, \bar{x} \pm \mathrm{SEM}$, n.s.) did not show significant difference, but individual muscle strength scores increased significantly compared with the control values measured at the beginning of the study (muscle strength before vs. after: $22.51 \pm 2.35 \mathrm{~kg}$ vs. $24.54 \pm 2.65 \mathrm{~kg}, \bar{x} \pm \mathrm{SEM}$, significant difference, $p=0.027)$. The results are shown in Fig. 1.

\section{Inter-group comparison of the responses to PT and PT $+N T$ interventions}

Comparing the intra-group changes of muscle strength and muscle mass in the PT and PT + NT groups following the 3-month interventions, it was found that the combined PT + NT intervention induced changes represented a positive and statistically significant shift in the 

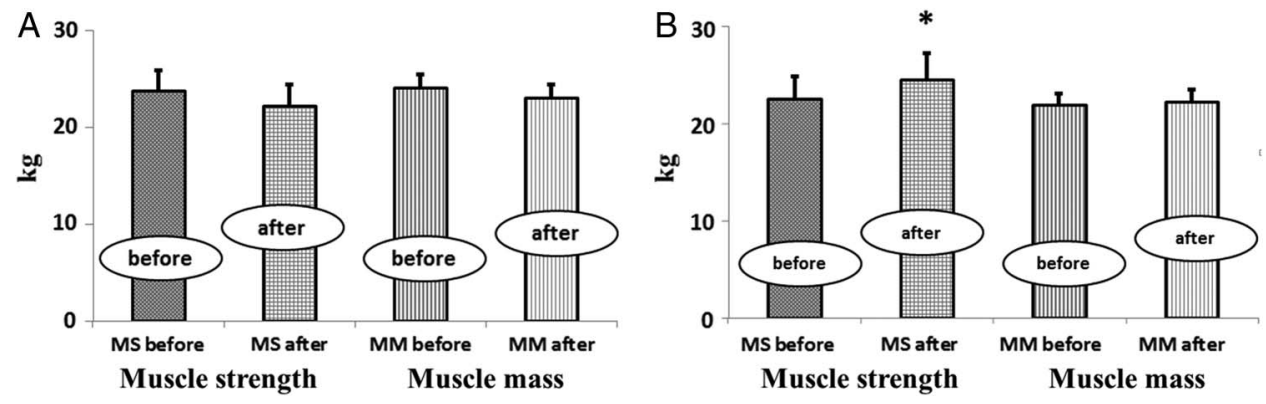

Fig. 1. Muscle strength $(\mathrm{kg})$ and muscle mass $(\mathrm{kg})$ values before and after the 3-month program in the group receiving regular and standardized physiotherapy (muscular exercise) (PT; see A) and the group receiving physiotherapy + special medical nutrition therapy (FortiFit) $(\mathbf{P T}+\mathbf{N T}$; see B) are shown as mean \pm SEM. Significant difference: ${ }^{*} p=0.027$

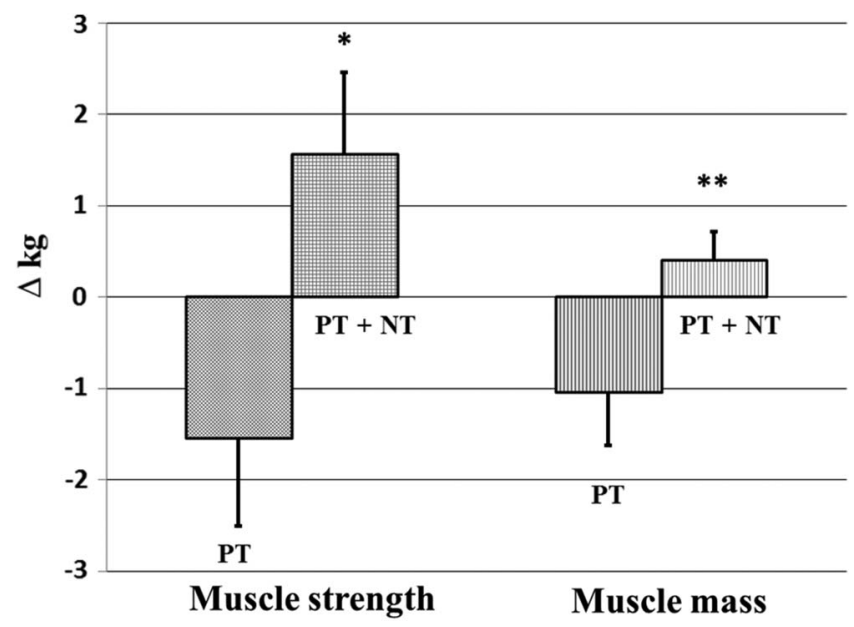

Fig. 2. Comparison of the changes induced by physiotherapy alone (group PT) and by the combined physiotherapy + medical nutrition therapy (group PT + NT) in muscle strength $(\bar{x} \pm \mathrm{SEM}, \mathrm{kg})$ and muscle mass ( $\bar{x} \pm$ SEM, $\mathrm{kg}$ ).

Significant differences: $* p=0.013$ and $* * p=0.038$

direction of skeletal muscle mass and strength increase when they were compared with the alterations induced by the single PT intervention (see Fig. 2).

Analysis $\left(\chi^{2}\right.$ test) on potential changes of the distribution of normal and pre-sarcopenic + sarcopenic cases in the two groups after the therapeutic interventions: as a final step, the post-interventional intra-group changes of the distribution of normal vs. pre-sarcopenic + sarcopenic conditions induced by PT or PT + NT were analyzed by the $\chi^{2}$ test. Then, the inter-group differences of therapeutic responses of PT group vs. PT + NT group were analyzed using the same test. The results are presented in Table I. The statistical analysis of the distribution of normal and pathologic conditions indicated no significant changes after the two different types of therapeutic interventions in either the PT or the PT + NT group. However, when these slight non-significant therapeutical distribution alterations of the two groups were compared by the $\chi^{2}$ test (inter-group comparison of the intra-group alterations), a statistically significant $(p<0.01)$ shift from pathological to normal condition of the musculature of the members of the PT + NT group was found when it was compared with the PT group. 
Table I. The distribution of the normal vs. pre-sarcopenic + sarcopenic conditions in the two groups before and after the PT and PT + NT interventions (intra-group differences) and the comparison of the therapeutic responses of the two groups (inter-group differences) by $\chi^{2}$ test

\begin{tabular}{|l|c|c|c|c|c|}
\hline & \multicolumn{5}{|c|}{ Condition distribution (NS vs. PS + S) } \\
\hline $\begin{array}{l}\text { Intervention } \\
\text { (groups) }\end{array}$ & & Before & After & $\begin{array}{c}\left.\text { Change } \chi^{2}\right) \\
\text { (intra-group } \\
\text { differences) }\end{array}$ & $\begin{array}{c}\text { Comparison of } \\
\text { changes (inter-group } \\
\text { differences) }\end{array}$ \\
\hline PT & NS & 11 & 9 & n.s. & $\begin{array}{c}\text { Significant difference } \\
p<0.001\left(\chi^{2}\right)\end{array}$ \\
\hline & $\mathrm{PS}+\mathrm{S}$ & $6(2+4)$ & $8(4+4)$ & & \\
\hline $\mathrm{PT}+\mathrm{NT}$ & $\mathrm{NS}$ & 3 & 7 & n.s. & \\
\hline & $\mathrm{PS}+\mathrm{S}$ & $14(3+11)$ & $10(3+7)$ & & \\
\hline
\end{tabular}

NS, no sarcopenia; PS, pre-sarcopenia; S, sarcopenia; $\chi^{2}$ : chi-square test

\section{Discussion}

The decrease of muscle mass and muscle strength seen in the aging population is an unavoidable part of physiological aging $(19,23)$. The progress of this process is vastly exacerbated by pathological risk factors, e.g., in the case of elderly residents with multiple chronic comorbidities in care or in nursing homes with higher prevalence of severe sarcopenia $(3,21,22)$, which has been recently defined by combined diagnostic criteria (14). The progression of sarcopenia leads to further complications, such as loss of independence and life-threatening gait instability, falls, frailty syndrome, and finally death $(1,18,21)$. Having regard to all these physiological-pathophysiological challenges, it is an important result of this study, that the combined physiotherapy + special nutritional therapy containing whey protein rich in essential amino acids - leucine - and vitamin D $(\mathrm{PT}+\mathrm{NT})$ resulted in a significant improvement of muscle strength in institutional care at high risk of pathological neuromuscular deterioration (14) and known for not always giving satisfactory therapeutic responses to muscle protective interventions (15). Beyond that, the importance of the special nutritional therapy (NT) in this therapeutic combination was shown by finding a positive shift in the changes of both the muscle mass and strength induced by the PT + NT intervention when it was compared with those induced by PT intervention alone. Although numerous encouraging findings have been available on the positive effects of enhanced physical activity (27), and adequate qualitative and increased quantitative uptake of proteins $(7,15,28,29)$, these procedures even in their combinations were often unsuccessful in the elderly people $(7,10,11)$ due to the low sensitivity to any anabolic stimulation of muscle protein synthesis (10) and the substantial and age dependently increasing biological differences (10) in the elderly population. The EWGSOP study's consensus definition of sarcopenia has more clearly defined, where the border lies between the physiological loss of muscle mass, strength, or performance and the pathological stage sarcopenia (14). There is a very high risk of progressive sarcopenia in the elderly population with comorbidities who are residing in long-term care facilities $(3,21,22)$ and in these advanced pathological stages of the muscular deterioration, weaker therapeutic responses must be expected. As this study included both patients with physiological loss of muscle mass, strength, and performances 
and ones with sarcopenia + pre-sarcopenia, it was also possible to test the capability of the single and combined therapeutic interventions for preventing or reversing sarcopenia. The $\chi^{2}$ test was an appropriate statistical method to compare the potential intra-group changes and inter-group differences regarding the prevalence of normal and pathological (pre-sarcopenic + sarcopenic) status. An important finding on the advantage of the combined PT + NT intervention compared with the changes induced by the physiotherapy (PT) intervention alone was that physiotherapy combined with FortiFit, whey protein-amino acid-leucine-vitamin nutritional mixture $(\mathrm{PT}+\mathrm{NT})$, had resulted in a shift to normal stages in the distribution of the normal vs. pre-sarcopenic + sarcopenic conditions. This shift could be interpreted as a significant relative advantage of PT + NT intervention either in preventing or reversing the stage of (pre)sarcopenia in addition to the muscle mass and strength results. To evaluate the significance of the latter findings, it must be emphasized that without therapeutic interventions, slow, but continuous and progressive deterioration of the musculature could be expected in the highly vulnerable elderly patients of the study.

Having considered all the findings of the study, it must be conceded that even the beneficial alterations induced by PT + NT combined intervention were rather modest, partial, or only relative advantages compared with the changes that resulted from the effect of PT intervention alone. This can be interpreted by such limitations of the study as low case numbers and the medium frequency of standardized physical training (twice a week). Another limitation of the study was the use of the BIA method (instead of DEXA), but using InBody analyzer was easy, non-invasive, relatively inexpensive, and could be performed on any elderly person because it was portable and there was no ionizing radiation during the measurement (31). The other explanation for missing more characteristic beneficial muscle protective effects even of the combined PT + NT therapy is the lack of a real control group. Creating a real control group with no physical activity in a long-term care facility (with presumably a natural steady decline of muscle mass and strength of the elderly subjects with comorbidities over 3 months) was not considered for ethical reasons. Thus, the evaluation of our therapeutic results was less sensitive in this highly vulnerable age group. But it could be argued that even the lack of post-interventional change of muscle parameters could be hypothetically interpreted as successful prevention of an expectable mild decline.

This study could demonstrate the effectiveness of the combined physiotherapy + special nutritive therapy (26). Both components of this combination seem important for the efficacy. Although the single PT intervention did not result in significant post-interventional changes in the observed muscular parameters, several studies refer to its significance in the efficacy of any PT + NT combination. For example, regular enhanced physical activity of elderly master-athletes (25) significantly reduced although could not fundamentally prevent, the loss of muscle mass and strength over time when they were compared with the control population. In turn, immobilization induces the resistance of muscles to anabolic stimulation (17), and the combinations of these two factors are the major contributors to the development and progression of sarcopenia (16).

Beyond this study, the muscle protective importance of the special NT intervention was also demonstrated by another examination: a 13-week intervention of a vitamin $\mathrm{D}$ and leucine-enriched whey protein oral nutritional supplement resulted in improvements in muscle mass and lower extremity function among sarcopenic elderly adults with limited mobility (4). 


\section{Conclusions}

Special nutrition intervention (fast protein, essential amino acids, leucine-enriched mixture with vitamin D) is necessary to accomplish muscle protective efficacy of regular physical exercise even in those elderly people who are at the highest risk of sarcopenia.

\section{Acknowledgements}

AM (dietician): study concept, design, assembly (measured the body composition and planned the medical nutrition therapy), data collection, and manuscript draft. IJS (physiotherapist): study concept, design, assembly (planned the physiotherapy and assessed the muscle strength and function), and data collection. AACs: study design, data interpretation, and manuscript draft. CsF: study concept, design (assessed the mental state of the patients at inclusion and later), and data interpretation. SzV: data analysis, data interpretation, and manuscript draft. BSz: study concept, design, assembly, data analysis, data interpretation, and approval of the final version of the manuscript. All authors have read and approved the final version of the manuscript. We also thank all the participants who have taken part in this study.

\section{Conflict of interest}

A. Molnár works as a part-time Medical Advisor at Nutricia in Budapest, Hungary. All other authors declare no conflict of interest.

\section{REFERENCES}

1. Batsis JA, Mackenzie TA, Barre LK, Lopez-Jimenez F, Bartels SJ: Sarcopenia, sarcopenic obesity and mortality in older adults: results from the National Health and Nutrition Examination Survey III. Eur J. Clin. Nutr. 68, 1001-1007 (2014)

2. Bauer J, Biolo G, Cederholm T, Cesari M, Cruz-Jentoft AJ, Morley JE, Phillips S, Sieber C, Stehle P, Teta D, Visvanathan R, Volpi E, Boirie Y: Evidence-based recommendations for optimal dietary protein intake in older people: a position paper from the PROT-AGE study group. J. Am. Med. Dir. Assoc. 14, 542-559 (2013)

3. Bauer JM, Kaiser MJ, Sieber CC: Sarcopenia in nursing home residents. J. Am. Med. Dir. Assoc. 9, 545-551 (2008)

4. Bauer JM, Verlaan S, Bautmans I, Brandt K, Donini LM, Maggio M, McMurdo ME, Mets T, Seal C, Wijers SL, Ceda GP, De Vito G, Donders G, Drey M, Greig C, Holmbäck U, Narici M, McPhee J, Poggiogalle E, Power D, Scafoglieri A, Schultz R, Sieber CC, Cederholm T: Effects of a vitamin D and leucine-enriched whey protein nutritional supplement on measures of sarcopenia in older adults, the PROVIDE study: a randomized, doubleblind, placebo-controlled trial. J. Am. Med. Dir. Assoc. 9, 740-747 (2015)

5. Baumgartner RN, Koehler KM, Gallagher D, Romero L, Heymsfield SB, Ross RR, Garry PJ, Lindeman RD: Epidemiology of sarcopenia among the elderly in New Mexico. Am. J. Epidemiol. 147, 755-763 (1998)

6. Biolo G, Cederholm T, Muscaritoli M: Muscle contractile and metabolic dysfunction is a common feature of sarcopenia of aging and chronic diseases: from sarcopenic obesity to cachexia. Clin. Nutr. 33, 737-748 (2014)

7. Boirie Y, Morio B, Caumon E, Cano NJ: Nutrition and protein energy homeostasis in elderly. Mech. Ageing Dev. 136-137, 76-84 (2014)

8. Borsheim E, Bui QU, Tissier S, Kobayashi H, Ferrando AA, Wolfe RR: Effect of amino acid supplementation on muscle mass, strength and physical function in elderly. Clin. Nutr. 27, 189-195 (2008)

9. Bozzetti F: Tailoring the nutritional regimen in the elderly cancer patient. Nutrition 31, 612-614 (2015)

10. Breen L, Phillips SM: Skeletal muscle protein metabolism in the elderly: interventions to counteract the 'anabolic resistance' of ageing. Nutr. Metab. 8, 68 (2011)

11. Candow DG, Forbes SC, Little JP, Cornish SM, Pinkoski C, Chilibeck PD: Effect of nutritional interventions and resistance exercise on aging muscle mass and strength. Biogerontology 13, 345-358 (2012)

12. Cederholm T, Bosaeus I, Barazzoni R, Bauer J, Van Gossum A, Klek S, Muscaritoli M, Nyulasi I, Ockenga J, Schneider SM, Muscaritoli M, Nyulasi I, Ockenga J, Schneider SM, de van der Schueren MA, Singer P: Diagnostic criteria for malnutrition - an ESPEN consensus statement. Clin. Nutr. 34, 335-340 (2015) 
13. Chale A, Cloutier GJ, Hau C, Phillips EM, Dallal GE, Fielding RA: Efficacy of whey protein supplementation on resistance exercise-induced changes in lean mass, muscle strength, and physical function in mobility-limited older adults. J. Gerontol. A Biol. Sci. Med. Sci. 68, 682-690 (2013)

14. Cruz-Jentoft AJ, Baeyens JP, Bauer JM, Boirie Y, Cederholm T, Landi F, Martin FC, Michel JP, Rolland Y, Schneider SM, Topinková E, Vandewoude M, Zamboni M: Sarcopenia: European consensus on definition and diagnosis: report of the European working group on sarcopenia in older people. Age Ageing 39, 412-423 (2010)

15. Deutz NE, Bauer JM, Barazzoni R, Biolo G, Boirie Y, Bosy-Westphal A, Cederholm T, Cruz-Jentoft A, Krznaric Z, Nair KS, Singer P, Teta D, Tipton K, Calder PC: Protein intake and exercise for optimal muscle function with aging: recommendations from the ESPEN expert group. Clin. Nutr. 33, 929-936 (2014)

16. Dickinson JM, Volpi E, Rasmussen BB: Exercise and nutrition to target protein synthesis impairments in aging skeletal muscle. Exerc. Sport Sci. Rev. 41, 216-223 (2013)

17. Glover EI, Phillips SM, Oates BR, Tang JE, Tarnopolsky MA, Selby A, Smith K, Rennie MJ: Immobilization induces anabolic resistance in human myofibrillar protein synthesis with low and high dose amino acid infusion. J. Physiol. 586, 6049-6061 (2008)

18. Hegerova P, Dedkova Z, Sobotka L: Early nutritional support and physiotherapy improved long-term selfsufficiency in acutely ill older patients. Nutrition 31, 166-170 (2015)

19. Holloszy JO: The biology of aging. Mayo Clin. Proc. 75 Suppl. S3-S8, discussion S8-S9 (2000)

20. Hughes VA, Frontera WR, Wood M, Evans WJ, Dallal GE, Roubenoff R, Fiatarone Singh MA: Longitudinal muscle strength changes in older adults: influence of muscle mass, physical activity, and health. J. Gerontol. A Biol. Sci. Med. Sci. 56, B209-B217 (2001)

21. Janssen I, Heymsfield SB, Ross R: Low relative skeletal muscle mass (sarcopenia) in older persons is associated with functional impairment and physical disability. J. Am. Geriatr. Soc. 50, 889-896 (2002)

22. Landi F, Liperoti R, Fusco D, Mastropaolo S, Quattrociocchi D, Proia A, Russo A, Bernabei R, Onder G: Prevalence and risk factors of sarcopenia among nursing home older residents. J. Gerontol. A Biol. Sci. Med. Sci. 67, 48-55 (2012)

23. Lauretani F, Russo CR, Bandinelli S, Bartali B, Cavazzini C, Di Iorio A, Corsi AM, Rantanen T, Guralnik JM, Ferrucci L: Age-associated changes in skeletal muscles and their effect on mobility: an operational diagnosis of sarcopenia. J. Appl. Physiol. 95, 1851-1860 (2003)

24. Luiking YC, Deutz NE, Memelink RG, Verlaan S, Wolfe RR: Postprandial muscle protein synthesis is higher after a high whey protein, leucine-enriched supplement than after a dairy-like product in healthy older people: a randomized controlled trial. Nutr. J. 13, 9 (2014)

25. McCracken CM: Muscle mass loss in active adults. Master's Theses, Department of Kinesiology of the School of Health, Physical Education, and Recreation, Indiana University (2009), https://scholarworks.iu.edu/dspace/ bitstream/handle/2022/6669/Thesis_Colleen_McCracken.pdf?sequence=1. Accessed 13 Nov 2015

26. Molnár A, Jónásné IS, Várbíró Sz, Székács B: Effect of physical exercise and medical nutrition in elderlies admitted to a care home. Clin. Nutr. 34 Suppl. 1, S165-S166 (2015)

27. Montero-Fernandez N, Serra-Rexach JA: Role of exercise on sarcopenia in the elderly. Eur. J. Phys. Rehabil. Med. 49, 131-143 (2013)

28. Morley JE, Argiles JM, Evans WJ, Bhasin S, Cella D, Deutz NE, Doehner W, Fearon KC, Ferrucci L, Hellerstein MK, Kalantar-Zadeh K, Lochs H, MacDonald N, Mulligan K, Muscaritoli M, Ponikowski P, Posthauer ME, Rossi Fanelli F, Schambelan M, Schols AM, Schuster MW, Anker SD: Nutritional recommendations for the management of sarcopenia. J. Am. Med. Dir. Assoc. 11, 391-396 (2010)

29. Paddon-Jones D, Rasmussen BB: Dietary protein recommendations and the prevention of sarcopenia. Curr. Opin. Clin. Nutr. Metab. Care 12, 86-90 (2009)

30. Patel HP, Syddall HE, Jameson K, Robinson S, Denison H, Roberts HC, Edwards M, Dennison E, Cooper C, Aihie Sayer A: Prevalence of sarcopenia in community-dwelling older people in the UK using the European Working Group on Sarcopenia in Older People (EWGSOP) definition: findings from the Hertfordshire Cohort Study (HCS). Age Ageing 42, 378-384 (2013)

31. Thibault R, Genton L, Pichard C: Body composition: why, when and for who? Clin. Nutr. 31(4), 435-447 (2012)

32. Wiswell RA, Hawkins SA, Jaque SV, Hyslop D, Constantino N, Tarpenning K, Marcell T, Schroeder ET: Relationship between physiological loss, performance decrement, and age in master athletes. J. Gerontol. A Biol. Sci. Med. Sci. 56, M618-M626 (2001) 